\title{
A practical testing battery to measure neurobehavioral ability among children with Fetal Alcohol Spectrum Disorder
}

\author{
Wendy O. Kalberg ${ }^{1}$, Philip A. May ${ }^{1,2}$, Jason Blankenship ${ }^{1}$, David Buckley ${ }^{1}$, J. Phillip Gossage ${ }^{1}$, and Colleen \\ M. Adnams ${ }^{3}$ \\ ${ }^{1}$ Center on Alcoholism, Substance Abuse and Addictions, The University of New Mexico, Albuquerque, NM, United States \\ ${ }^{2}$ The University of North Carolina at Chapel Hill, Gillings School of Public Health, Nutrition Research Institute, Kannapolis, NC, United States \\ ${ }^{3}$ Departments of Psychiatry and Pediatrics, The University of Cape Town, Cape Town, Republic of South Africa
}

\begin{abstract}
Aim: To determine a brief, practical battery of tests that discriminate between children with a fetal alcohol spectrum disorder (FASD) and unexposed controls.

Design: Children received dysmorphology exams and a targeted battery of cognitive and behavioral tests, and their mothers were interviewed about maternal risk factors. Children diagnosed with an FASD and children unexposed to alcohol prenatally were compared on cognitive-behavioral test results.
\end{abstract}

Setting: A community in the Western Cape Province of South Africa.

Participants: Sixty-one first-grade children with FASD and 52 matched normal controls.

Measures: Statistical analyses of maternal drinking behavior and the children's test performances.

Findings: Self-reported maternal drinking patterns before, during, and after pregnancy were used to confirm prenatal exposures to alcohol in the group of children diagnosed with FASD. With this sample of children diagnosed with FASD and completely unexposed controls, the adverse effects of maternal drinking on children's performance are corroborated. Results of the battery of standardized cognitive and behavioral tests indicate highly significant differences $(p \leq .001)$ between the two groups on intelligence, perceptual motor skills, and planning, and on logical, spatial, short term, long term, and working memory abilities. Furthermore, a binary logistical regression model of only three specific cognitive and behavioral tests, including Digit Span A+B (Wald = 3.90), Absurd Situation (Wald = 4.73), and Word Association (Wald $=6.85$ ) correctly classified $77.6 \%$ of the child participants as FASD or controls.

Conclusions: A brief, practical set of tests can discriminate between children with and without FASD and provide useful information for interventions for affected children.

For over 15 years, Fetal Alcohol Spectrum Disorders (FASDs) have been the focus of collaborative studies in South Africa (ZA) which have contributed to an enhanced cross-cultural and population-based understanding of FASD. Because prenatal alcohol exposure impacts the developing fetus in a complex manner and the diagnosis of the spectrum of disorders is not straightforward, these studies of large groups of heavily alcohol-exposed children in ZA have advanced understanding of the range of effects on children and their ability to function effectively in the world. This article presents data from a study in the Western Cape Province (WCP) of ZA, where a practical battery (commonly used and easily administered) of standardized tests was used to investigate the cognitive and behavioral patterns of a group of children who had been diagnosed with FASD using the Revised IOM Diagnostic criteria (Hoyme et al., 2005).

The diagnosis of Fetal Alcohol Syndrome (FAS) was first formalized and published in 1973 (Jones \& Smith, 1973), and further diagnostic delineation continues today. There is considerable agreement regarding the important individual physical and behavioral components constituting the syndrome (Aase, 1994; Aase, Jones, \& Clarren, 1995; Astley \& Clarren, 2000; Chudley et al., 2005; Hoyme et al.,

Correspondence: Wendy O. Kalberg or Philip A. May, Center on Alcoholism, Substance Abuse and Addictions, The University of New Mexico, 2650 Yale Blvd. SE, Albuquerque, NM, United States, 87106. Telephone: 505-925-2306 or 2307. Fax: 505-925-2313 or 505-925-2351. E-mail: wkalberg@unm.edu or pmay@unm.edu Financial support: This project was funded by the National Institutes of Health (NIH), specifically the National Institute on Alcohol Abuse and Alcoholism (NIAAA) via RO1 AA 09440, RO1/UO1 AA11685, UO1 AA14786, and RO1 AA15134.

Keywords: Fetal Alcohol Spectrum Disorders (FASD), cognitive/behavioral testing, diagnosis, alcohol abuse 
2005; Sokol \& Clarren, 1989; Stratton, Howe, \& Battaglia, 1996).

According to the Institute of Medicine (IOM), children with FAS have a characteristic pattern of (1) facial and body dysmorphology, (2) delayed physical growth and development, and (3) specific mental and behavioral deficits (Stratton et al., 1996). For a diagnosis of FAS, all three categories of problems must be present, and the diagnosis should be made only after excluding other genetic and teratogenic anomalies (Hoyme et al., 2005). All IOM-prescribed diagnoses of the FASD spectrum were utilized in this population-based study: FAS and Partial Fetal Alcohol Syndrome (PFAS), Alcohol-Related Neurodevelopmental Deficits (ARND), and AlcoholRelated Birth Defects (ARBD) (Warren et al., 2004).

Prenatal alcohol exposure can lead to brain damage resulting in cognitive and behavioral impairments. Specific deficit areas in the population of individuals exposed to alcohol prenatally (Conry, 1990; Kodituwakku et al., 2006) include:

- general intelligence (Bailey et al., 2004; Jacobson, Jacobson, Sokol, Chiodo, \& Corobana, 2004; Mattson \& Riley, 1998; Streissguth et al., 2004),

- executive functioning (Kodituwakku, Handmaker, Cutler, Weathersby, \& Handmaker, 1995; Kodituwakku, Kalberg, \& May, 2001; Kopera-Frye, Dehaene, \& Streissguth, 1996; Mattson et al., 1999; Schonfeld, Paley, Frankel, \& O’Connor, 2006),

- information processing (Aragon et al., 2008; Burden, Jacobson, \& Jacobson, 2005; Streissguth, 2007),

- attention (Coles et al., 1997; Coles, Platzman, Lynch, \& Freides, 2002; Mattson, Calarco, \& Lang, 2006; Steinhausen \& Spohr,1998),

- language (both receptive and expressive) (Janzen, Nanson, \& Block, 1995; Mattson \& Roebuck, 2002; McGhee, Bjorkquist, Riley, \& Mattson, 2008),

- learning and memory (Kaemingk, Mulvaney, \& Halverson, 2003; Mattson \& Riley, 1999; RoebuckSpencer \& Mattson, 2004),

- motor skills (Adnams et al., 2001; Kalberg et al., 2006; Korkman, Kettunen, \& Autti-Ramo, 2003),

- and behavior (Bishop, Gahagan, \& Lord, 2007; Nash et al., 2006; Thomas, Kelly, Mattson, \& Riley, 1998; Whaley, O’Connor, \& Gunderson, 2001).

Additionally, Mattson et al. (2010) indicated that tests of executive functioning and spatial processing distinguish children with prenatal alcohol-exposure and the physical features of FASD from children with no prenatal exposure. Aragon et al. (2008) and Kodituwakku (2009) summarized the cognitive-behavioral phenotype associated with FASD as a generalized deficit in processing complex information, stemming from deficiencies in recruiting multiple regions of the brain to complete complex tasks.

\section{South African FASD Epidemiology Studies}

The first population-based study in this community produced the highest rates of FAS ever reported at that time: over 40.5 to 46.4 per 1,000 (May et al., 2000;
Viljoen, Croxford, Gossage, \& May, 2002). Two subsequent studies in this same community also found extremely high rates of FAS and PFAS-65.2 to 74.2 per 1,000 (May et al., 2005; Viljoen et al., 2005) and 68.0 to 89.2 per 1,000 (May et al., 2007, 2008)—as have other studies using similar methods in other ZA communities (Urban et al., 2008; Viljoen, Craig, Hymbaugh, Boyle, \& Blount, 2003). These studies have raised many questions about the universal characteristics of FASD (Adnams et al, 2001). For example, are deficits seen in children with FASD in ZA the same as deficits in children with FASD from other western countries? Adnams et al. (2001) demonstrated that, when socioeconomic status, maternal depression, low parental education, violence and social disruption were controlled for, children with FASD in a ZA community demonstrated a pattern of cognitive-motor deficits similar to those reported in the literature.

This article summarizes testing results of a well-matched sub-sample of children with FASD and unexposed controls from a second, active-case ascertainment epidemiology study in a first-grade cohort. The goal of the study was to define a battery of tests that would discriminate between children with an FASD and unexposed controls. The rationale for the chosen battery was to determine a brief and practical set of cognitive and behavioral measures, commonly used and available to school psychologists and developmental clinicians, that identify the deficits common to all children with confirmed prenatal exposure to alcohol and a diagnosis of FASD.

The hypothesis was that children with FASD perform poorly on tests that require greater mental effort and complex thinking. For example, cognitive planning tasks require conceptual set shifting and working memory, logical memory, and later recall. Although other studies have demonstrated that a set of neuropsychological measures can discriminate between exposed children and unexposed controls, the battery of tests used in many of those studies are extensive, quite time-consuming, and expensive, and often they are not readily available to those working in schools and communities (Mattson et al., 2010).

Many children affected with FASD are currently without appropriate educational and learning supports. It is necessary to create bridges between the empirical evidence and real world practice to help these children. Evaluation of deficits for the affected children is the first step in determining a need for services. The field will benefit from empirically-determined evaluation guidelines for deficit areas of children with FASD. This study examines a battery of tests that target the known deficits in this population, and that are commonly available to school psychologists and developmental clinicians.

\section{Method}

\section{Identifying Children with FASD in Schools}

In the parent epidemiology study, $96 \%$ of all enrolled students in the targeted community's schools received 
guardian consent to participate. Screening and dysmorphology exams were completed for all consented children. After dysmorphology examinations, 92 children were developmentally tested and maternal prenatal risk factor questionnaires were completed. Those administering the developmental tests and the maternal interviewers were blinded to the reason for study entry and to any results from the other study domains. Full methodology for the parent study is found in Viljoen et al. (2005).

\section{Child Control Group}

Control children for the parent epidemiology study ( $n=$ 146) were randomly selected from consented first grade students enrolled in the same schools. Identical exams and testing were performed on subjects and potential controls (Viljoen et al., 2005). If, having gone through the examination and testing process, a selected child was not found to have an FASD, then he/she served as a control. Since some of the mothers of the normal controls were subsequently found to have consumed alcohol during the index pregnancy, and because prenatal alcohol exposure may impact performance on neuropsychological tests, a matching process was initiated to make sure that one completely unexposed control child was matched, by age (within 12 months) and sex, to each child with an FASD. This necessitated recruitment of 25 additional, unexposed children who met the age and sex criteria. These children were given the same diagnostic exams and testing as the 36 children who originated from the random selection. This resulted in a sample of 61 seemingly unexposed controls; however, a closer look at the maternal interviews revealed that 9 of those 61 mothers had drunk some alcohol during pregnancy. After their children were eliminated, the remaining sample consisted of 52 unexposed control children, reported on here.

\section{Maternal Data for Cases and Controls}

Available mothers of children with an FASD and controls were interviewed. Fifty-three of the 61 mothers of the FASD children included in this study were interviewed. For the remaining eight, prenatal alcohol consumption data were obtained via collateral sources (May et al, 2005, May, Hymbaugh, Aase, \& Samet, 1983; Streissguth, Clarren, \& Jones, 1985). Maternal data presented here focus primarily on confirmation of maternal drinking for case assessment/ diagnosis. A detailed profile of maternal risk factors for FASD in this community are reported elsewhere (May et al., 2005; 2008; Viljoen et al., 2002). Structured maternal interviews contained items covering reproduction; alcohol use before, during and after the index pregnancy; socioeconomic status (SES); demographic variables; diet and nutrition; and physical status of the mother. Protocols utilized drinking questions in a timeline follow-back methodology (Sobell et al., 1988; 2001) to elicit accurate reporting of alcohol consumed. All interviews were administered by experienced, Afrikaans-speaking interviewers.

\section{Case Conferences for Final Diagnoses}

Final diagnoses for all children (cases and controls) were made at a case conference, based on dysmorphology exams, developmental testing, and maternal interviews documenting alcohol exposure and other risk factors (see Hoyme et al., 2005; May et al., 2000; 2007; Viljoen et al, 2005).

\section{Figure 1}

\section{Testing Battery and Ability tested}

\begin{tabular}{|c|c|}
\hline \multicolumn{2}{|l|}{ BEHAVIOR } \\
\hline PBCL-36 & - behaviors most often seen in children with FAS \\
\hline \multicolumn{2}{|l|}{ GENERAL INTELLIGENCE } \\
\hline Raven Progressive Matrices & $\begin{array}{l}\text { Fluid intelligence; } \\
\text { • general reasoning, problem-solving and induction }\end{array}$ \\
\hline Test of Reception of Grammar (TROG) & $\begin{array}{l}\text { Crystallized intelligence; } \\
\text { - ability to understand grammatical constructs with little verbal effort }\end{array}$ \\
\hline Story Memory & - short-term memory, verbal elaboration, and summarization \\
\hline Visual-Motor Integration (VMI) & - visual perception and the integration of visual-perceptual and motor abilities \\
\hline \multicolumn{2}{|c|}{$\begin{array}{l}\text { SUBTESTS REQUIRING GREATER MENTAL EFFORT } \\
\text { (self-monitoring, complex planning, attention, and maintenance of multiple pieces of information in working memory) }\end{array}$} \\
\hline Digit Span A, Forward & - short-term sequential auditory memory and attention \\
\hline Digit Span B, Backward & - conceptual set shifting and working memory, logical memory and later recall \\
\hline Absurd Situation & - recognition of right and wrong and exhibition of impulse control \\
\hline Word Association & - organize, abstract and find relationships that are not at first obvious \\
\hline
\end{tabular}




\section{Test Battery}

Intelligence tests, perceptual motor tests, planning tests, and logical, spatial, short term, long term, and working memory tasks were selected (see Figure 1). The tests are normed and standardized, except for the Personal Behavior Checklist, a frequently used checklist of children with FASD (Streissguth, Bookstein, Barr, Press, \& Sampson, 1998). The battery of standardized tests chosen and administered measure abilities shown to be affected in prenatally-exposed children, and are generally available and practical to use by school and clinic staff.

Intellectual abilities. The test battery selected included a measure of fluid intelligence, The Raven Progressive Matrices (Raven, 1947), for children six through 16 years, measuring a person's ability to form perceptual relations and reason by analogy. This nonverbal test was chosen for this South African population to minimize the verbal comprehension load on the subject. The Raven has been used extensively for studies in diverse cultures because of the culturally-fair aspect of the measure (Edwards et al., 2010; Sattler, 2001; Sizemore \& Amler, 1996). The Test for the Reception of Grammar (TROG) (Bishop, 1989) measures a child's ability to understand grammatical constructs using a multiple-choice format which requires a minimal effort from the child. This is desirable for this student population, as it provides an opportunity for the child to demonstrate his/her understanding of grammatical constructs separate from verbal abilities.

In addition, selected subtests from the Junior South African Individual Scales (JSAIS) (Robinson, 1989) were administered: Story Memory, Absurd Situation, Word Associations, and Digit Span (forward and backward). The JSAIS was developed to provide a profile of an English- or Afrikaans-speaking child's cognitive abilities. The battery is standardized for school-aged Afrikaans-speaking children from six years to eight years and 11 months, making it very applicable for the children in this study. The selected subtests were chosen to target empiricallybased deficit areas in prenatally exposed children. It was hypothesized that these subtests tax the brain by requiring the involvement of multiple brain regions to successfully complete abstract reasoning, logical thinking, and simple memory/working memory tasks.

Motor and visual-perceptual abilities. The BeeryBuktenica Developmental Test of Visual-Motor Integration (VMI) (Beery et al., 1997) was used to assess visual and motor integration abilities and evaluate visual perception. The VMI is a non-verbal test that is used among diverse environmental, educational, cultural, and linguistic groups.

Behavior. Behavior was assessed using the Personal Behavior Checklist (PBCL-36, Teacher Report Form) translated into Afrikaans (Streissguth et al, 1998). The PBCL-36 is a checklist developed to assess the behavior of children with FASD. The 36 questions resulted from the most commonly reported behaviors among families of children with FAS. The tool is not standardized, but it has adequate test-retest reliability.

\section{Statistical Analyses}

Data were analyzed using SPSS Version 19.0 (SPSS Inc., 2010). Chi square tests were performed on categorical level data, and one-way analysis of variance tests on interval level data, as noted in Tables 1, 2, and 3. Although we used standardized scores for the analysis, we also ran an analysis of covariance controlling for age to make certain our group significant differences were not accounted for by the age differential (see Table 3). Binomial logistic regression was used to determine which tests predict classification in either the FASD or Control group (see Table 4).

\section{Results}

\section{Sample}

Sixty-one children with an FASD diagnosis and 52 nonexposed controls were used for this analysis. Of the 61 affected children, 37 or $60.7 \%$ were FAS, 16 or $26.2 \%$ were PFAS, and 8 or $13.1 \%$ were ARND (See Table 1); 28 were male (45.9\%) and 33 were female (54.1\%), with an average age of 73 months. The average age of the 52 unexposed control group children was 82 months; 23 were male (44.2\%) and 29 were female (55.8\%).

Table 1 compares physical and dysmorphology variables between FASD and control children. With the exception of sex, all variables discriminate between FASD and Control children at $p \leq .001$.

Table 2 compares self-reported alcohol use by mothers of FASD children with mothers of control children. Each maternal/paternal risk factor-including drinking before and after the index pregnancy, average number of drinks per day and drinking by each trimester, and fathers' drinking problems-significantly discriminates between mothers of FASD children and of control children.

Table 3 compares FASD and control children on developmental and behavioral tests. With the exception of the Story Memory Mental Age score, all neuropsychological test results are significant, including TROG, Raven non-verbal ability, and PBCL-36 personal behavior.

Binary logistic regression was performed to determine the cognitive and behavioral test variables that best discriminate between participants in the FASD and control groups. The Wald statistic, which is based on a $z$ score, is used to test the significance of each predictor variable in the model (Table 4), showing the relative contribution of each. A model containing Digit Span A+B, absurd situation, and word associations correctly classified $77.6 \%$ of the child participants as either FASD or control. 
Table 1

Child physical and dysmorphology comparisons, FASD cases versus controls

\begin{tabular}{|c|c|c|c|c|c|}
\hline Child Variables & $\begin{array}{c}\text { FASD Children } \\
\qquad(N=61)^{1}\end{array}$ & $\begin{array}{l}\text { Control Children } \\
\qquad(N=52)\end{array}$ & Statistical Test & $d f$ & $p$ \\
\hline \multicolumn{6}{|l|}{ Sex $(\%)$} \\
\hline Males & 45.9 & 44.2 & & & \\
\hline Females & 54.1 & 55.8 & $\chi^{2}=0.03$ & 1 & 1.000 \\
\hline \multicolumn{6}{|l|}{ Age (months) } \\
\hline Mean (SD) & $78.5(7.6)$ & $88.3(11.0)$ & $F=30.81$ & $1 / 111$ & .000 \\
\hline \multicolumn{6}{|l|}{ Height (cm) } \\
\hline Mean (SD) & $108.5(4.6)$ & 119.8 (7.9) & $F=88.79$ & $1 / 111$ & .000 \\
\hline \multicolumn{6}{|l|}{ Weight (kg) } \\
\hline Mean (SD) & $15.7(1.7)$ & $22.5(5.1)$ & $F=93.61$ & $1 / 111$ & .000 \\
\hline \multicolumn{6}{|l|}{ Occipital Circumference } \\
\hline$(\mathrm{OFC}$; in cm) Mean (SD) & $48.1(1.3)$ & $51.3(1.6)$ & $F=130.50$ & $1 / 111$ & .000 \\
\hline \multicolumn{6}{|l|}{ Palpebral Fissure Length (cm) } \\
\hline Mean (SD) & $2.25(.12)$ & $2.54(.18)$ & $F=97.16$ & $1 / 108$ & .000 \\
\hline Smooth Philtrum² (\%) & 78.7 & 34.7 & $\chi^{2}=21.76$ & 1 & .000 \\
\hline Narrow Vermilion Border ${ }^{3}$ (\%) & 70.5 & 6.1 & $\chi^{2}=46.27$ & 1 & .000 \\
\hline \multicolumn{6}{|l|}{ Total Dysmorphology Score } \\
\hline Mean (SD) & $17.1(4.5)$ & $5.2(4.3)$ & $F=196.03$ & $1 / 108$ & .000 \\
\hline
\end{tabular}

Table 2

Maternal/paternal risk factor comparisons, FASD cases versus controls

\begin{tabular}{|c|c|c|c|c|c|}
\hline Maternal/Paternal Variables & $\begin{array}{c}\text { Mothers of } \\
\text { FASD Children } \\
(N=61)\end{array}$ & $\begin{array}{c}\text { Mothers of } \\
\text { Control Children } \\
(N=52)\end{array}$ & Statistical Test & $d f$ & $p$ \\
\hline Drinking before index pregnancy (\%) & 85.4 & 4.1 & $X^{2}=65.00$ & 1 & .000 \\
\hline $\begin{array}{l}\text { Drinking indicator—overall reported } \\
\text { drinking during pregnancy (\%) }\end{array}$ & 92.0 & 0.0 & $X^{2}=84.21$ & 1 & .000 \\
\hline $\begin{array}{l}\text { Average number of drinks per day } \\
\text { (during pregnancy) }\end{array}$ & 5.4 & 0.0 & $F=52.16$ & $1 / 93$ & .000 \\
\hline $\begin{array}{l}\text { Consumed } 3 \text { drinks or more per } \\
\text { occasion during pregnancy (\%) }\end{array}$ & 68.0 & 0.0 & $\chi^{2}=50.75$ & 1 & .000 \\
\hline $\begin{array}{l}\text { Consumed } 5 \text { drinks or more per } \\
\text { occasion during pregnancy (\%) }\end{array}$ & 60.0 & 0.0 & $\chi^{2}=42.18$ & 1 & .000 \\
\hline Current drinker in last year (\%) & 76.0 & 4.1 & $\chi^{2}=53.16$ & 1 & .000 \\
\hline \multicolumn{6}{|l|}{ Drank during trimesters (\%) } \\
\hline $1^{\mathrm{st}}$ & 92.0 & 0.0 & $X^{2}=84.21$ & 1 & .000 \\
\hline $2^{\text {nd }}$ & 92.0 & 0.0 & $X^{2}=83.23$ & 1 & .000 \\
\hline $3^{\text {rd }}$ & 88.0 & 0.0 & $X^{2}=74.73$ & 1 & .000 \\
\hline \multicolumn{6}{|l|}{ Father's data } \\
\hline $\begin{array}{l}\text { Fathers of Index Children with } \\
\text { drinking problems in past (\%) }\end{array}$ & 35.7 & 3.4 & $X^{2}=10.23$ & 1 & .001 \\
\hline
\end{tabular}


Table 3

Mean standardized ${ }^{a}$ scores on developmental and Behavioral Indicators of Children with FAS versus Controls, Wave II

\begin{tabular}{|c|c|c|c|c|c|c|}
\hline Child Variables & $\begin{array}{c}\text { FASD } \\
\text { Mean }(S D) \\
(N=61)\end{array}$ & $\begin{array}{l}\text { Controls Mean } \\
(S D)(N=52)\end{array}$ & Test Score & $d f$ & $p$ & $\begin{array}{l}\text { ANCOVA controlling } \\
\text { for age } \\
\text { Does test performance } \\
\text { vary significantly by } \\
\text { child's age? }\end{array}$ \\
\hline \multicolumn{7}{|l|}{ Developmental Traits } \\
\hline Verbal Ability ${ }^{\mathrm{b}}$ & $6.6(9.5)$ & $20.3(20.7)$ & $F=21.57$ & $1 / 110$ & .000 & No; $F=.616, p=.434$ \\
\hline Non-Verbal Ability & $13.0(12.8)$ & $24.2(19.5)$ & $F=13.28$ & $1 / 111$ & .000 & No; $F=.318, p=.574$ \\
\hline PBCL-36 & $14.2(8.1)$ & $6.7(6.4)$ & $F=21.96$ & $1 / 94$ & .000 & No; $F=.304, p=.583$ \\
\hline VMI & $68.0(12.4)$ & $79.3(19.3)$ & $F=14.10$ & $1 / 111$ & .000 & No; $F=.3 .32, p=.071$ \\
\hline $\begin{array}{l}\text { Digit Span A, Total } \\
\text { Score }\end{array}$ & $5.8(2.2)$ & $7.6(2.3)$ & $F=18.29$ & $1 / 111$ & .000 & No; $F=.995, p=.321$ \\
\hline $\begin{array}{l}\text { Digit Span B, Total } \\
\text { Score }\end{array}$ & $1.1(1.4)$ & $2.1(1.7)$ & $F=11.17$ & $1 / 111$ & .001 & No; $F=1.23, p=.270$ \\
\hline $\begin{array}{l}\text { Digit Span AB, Scaled } \\
\text { Score }\end{array}$ & $6.9(2.9)$ & $10.3(3.2)$ & $F=20.79$ & $1 / 66$ & .000 & No $; F=.293, p=.590$ \\
\hline $\begin{array}{l}\text { Absurd Situation, Scaled } \\
\text { Score }\end{array}$ & $55.6(13.1)$ & $69.3(15.7)$ & $F=25.20$ & $1 / 111$ & .000 & No; $F=.926, p=.340$ \\
\hline $\begin{array}{l}\text { Word Association, } \\
\text { Scaled Score }\end{array}$ & $60.2(14.9)$ & $69.2(13.6)$ & $F=11.00$ & $1 / 111$ & .001 & No; $F=.290, p=.592$ \\
\hline $\begin{array}{l}\text { PBCL-36, Teacher- } \\
\text { Rated }\end{array}$ & $12.3(7.5)$ & $6.3(5.9)$ & $F=21.10$ & $1 / 110$ & .000 & No; $F=.1 .01, p=.316$ \\
\hline $\begin{array}{l}\text { Story Memory, Scaled } \\
\text { Score }\end{array}$ & $65.9(18.6)$ & $70.9(21.8)$ & $F=1.01$ & $1 / 66$ & .318 & No; $F=.062, p=.805$ \\
\hline $\begin{array}{l}\text { Total Dysmorphology } \\
\text { Score** }\end{array}$ & $17.1(4.5)$ & $5.2(4.3)$ & $F=196.03$ & $1 / 111$ & .000 & \\
\hline $\begin{array}{l}\text { Head Circumference } \\
\text { (OFC) }\end{array}$ & $48.1(1.3)$ & $51.3(1.6)$ & $F=130.35$ & $1 / 111$ & .000 & \\
\hline
\end{tabular}

Table 4

Binary logistic regression of cognitive and behavioral testing to predict classification in FASD vs control group

\begin{tabular}{lccc}
\hline Variable & Wald & $\boldsymbol{d f}$ & $\boldsymbol{p}$ \\
\hline Digit Span A+B, scaled score & 3.90 & 1 & .048 \\
Absurd Situation, scaled score & 4.73 & 1 & .030 \\
Word Association, scaled score & 6.85 & 1 & .009 \\
\hline
\end{tabular}

$R^{2}=.36$ (Cox \& Snell), .48 (Nagelkerke). Model $\chi^{2}(3)=30.10, p<.001$

Overall ability of model to correctly classify participants as FASD or Control $=77.6 \%$

\section{Discussion}

Defining a battery of standardized tests that is useful for the FASD population is a vital goal globally; however, it is of particular importance in ZA and other under-served populations where resources are scarce and research has shown FASD to be both prevalent and severe. Most classrooms in ZA have multiple numbers of affected children enrolled, and children with an FASD can benefit from classroom and learning support (Adnams, 2008). The determination of needed supports begins with an accurate evaluation of each child's learning strengths and challenges.

Using maternal interview data, we were able to compare the testing results of definitively diagnosed children with those who were not exposed to alcohol at all. The battery 
of tests used was comprehensive, yet not lengthy or cumbersome. We included measures of verbal and nonverbal intelligence, visual-motor perception, behavior, and select subtests of the JSAIS felt to be discriminating for this population. With only one exception, the difference between the two groups was highly significant on all testing measures.

The JSAIS subtests-The Absurd Situation, Word Association, and Digit Span-all discriminated well between the groups. The Absurd Situations subtest requires the subject to look at a picture and recognize what is going on in the picture. Each picture has an incongruity that the subject is required to determine. In order to do this accurately, the subject must perceive detail correctly, requiring alertness, attention and concentration, inference, knowledge of science and geography, and social understanding. Conceptually, the subject must have some understanding of what is right and wrong and must exhibit impulse control in order to correctly respond (Sattler, 2001).

To be successful with the Word Associations subtest, the subject must perceive the common elements of the paired words and bring those elements together into a concept. This measures concept formation and the ability to place objects and events together in meaningful groups (Lyon, 1995). In order to do this, the subject must organize, abstract, and find relationships that are not at first obvious. Memory is involved, and success can be related to the interests of the subjects and their cultural opportunities.

Finally, Digit Span forward and Digit Span backward are considered separately, as they tap into different abilities. Digit Span forward involves sequential processing and short-term memory. Digit Span backward involves planning, sequential processing and working memory (Borkowsi \& Burke, 1996, Duncan et al., 2012). Working memory requires the subject to hold information in mind and manipulate the information into a different sequence or form before responding, requiring great mental effort and complex thinking.

The Story Memory subtest did not discriminate well between affected and unaffected children. The Absurd Situations, Digit Span, and Word Associations subtests, on the other hand, did discriminate well; they require more complex cognitive processes, difficulty with which is described by a number of researchers as a hallmark of children with an FASD (Aragon et al., 2008, Kodituwakku et al., 2006; Kodituwakku, 2009; Duncan et al, 2012).

The binary logistic regression analysis revealed that the JSAIS subtests of word associations, absurd situation, and digit span correctly classified $77.6 \%$ of the subjects with an FASD. These types of subtests are embedded, not only in the JSAIS, but within most well-normed, easily accessible, and widely-used intelligence tests, such as the Wechsler Scales (Wechsler, 2003), and can therefore be used in a sensitive fashion for other populations.

\section{Limitations}

It is important to note the limitations of this study. Although we attempted to administer a comprehensive yet feasible battery of tests, there were some aspects of performance that were not or were minimally evaluated. For example, the battery did not include a testing tool that looked at mathematical ability, a known area of difficulty for children affected by prenatal alcohol exposure. In addition, we did not include a comprehensive measure of behavior. Evaluation and assessment for appropriate educational programming should also include measures of academic performance and behavior. It would, therefore, be recommended that a comprehensive measure of academic performance and a behavioral measure be paired with this proposed battery of tests.

\section{Conclusion}

It is possible to utilize a practical and readily available set of evaluation tools to determine a learning profile for children diagnosed with an FASD. In most school districts in the U.S. and ZA, evaluations are conducted to better understand an individual child's strengths and areas of need. Well-known, frequently used, comprehensive tools and subtests measuring the domains of executive functioning, information processing, abstract reasoning, and complex thinking can be used effectively to evaluate children with a diagnosis within FASD, to determine if they are indeed struggling with tasks that require higher-order, more complex cognitive processes. This assessment information could assist schools in providing the appropriate learning supports for affected children.

\section{Acknowledgements:}

Appreciation goes to the National Institutes of Health (NIH), specifically the National Institute on Alcohol Abuse and Alcoholism (NIAAA), who funded this project via RO1 AA 09440, RO1/UO1 AA11685, UO1 AA14786, and RO1 AA15134.

Additional thanks go to Loretta Hendricks, whose tireless work locating and transporting children for the study was instrumental to its success. Also, the authors would like to acknowledge the professional input from Ansie Kitching, Rubin Adams, and Piyadasa Kodituwakku.

\section{References}

Aase, J. M. (1994). Clinical recognition of FAS, difficulties of detection and diagnosis. Alcohol Health and Research World, 18, 5-9.

Aase, J. M., Jones, K. L., \& Clarren, S. K. (1995). Do we need the term "FAE"? Pediatrics, 95, 428-430.

Adnams, C. M., Kodituwakku, P., Hay, A., Molteno, C., Viljoen, D., \& May, P. A. (2001). Patterns of cognitive-motor development in children with FAS from a community in South Africa. Alcoholism: Clinical and Experimental Research, 25, 557-562. 
Annett, M. (1970). The growth of manual preference and speed. British Journal of Psychology, 61, 545-558.

Aragon, A. S., Kalberg, W. O., Buckley, D., Barela-Scott, L. M., Tabachnick, B. G., \& May, P. A. (2008). Neuropsychological study of FASD in a sample of American Indian children. Processing simple versus complex information. Alcoholism: Clinical and Experimental Research, 32, 2136-2148. doi: 10.1111/ j.1530-0277.2008.00802.x

Armstrong, E. M. (2003). Conceiving risk, bearing responsibility. Fetal alcohol syndrome and the diagnosis of moral disorder. Baltimore, MD, United States: The Johns Hopkins Press.

Astley, S. J. \& Clarren, S. K. (2000). Diagnosing the full spectrum of fetal alcohol-exposed individuals. Introducing the 4-digit diagnostic code. Alcohol, 35, 400-410.

Bailey, B. N., Delaney-Black, V., Covington, C. Y., Ager, J., Janisse, J., Hannigan, J. H., \& Sokol, R. J. (2004). Prenatal exposure to binge drinking and cognitive and behavioral outcomes at age 7 years. American Journal of Obstetrics and Gynecology, 191, 1037-1043.

Beery, E. B., Buktenica, N. A., \& Beery, N. A. (1997). Beery-Buktenica Developmental Test of visual-motor integration ( $5^{\text {th }}$ ed.). San Antonio, TX, United States: Psych Corp, Pearson Publishing.

Bishop, D. V. M. (1989). Test for reception of grammar. Manchester, United Kingdom: University of Manchester Press.

Bishop, S., Gahagan, S., \& Lord, C. (2007). Re-examining the core features of autism. A comparison of autism spectrum disorder and fetal alcohol spectrum disorder. Journal of Child Psychology and Psychiatry, 48, 1111-1121. doi: 101111/j.1469-7610.2007.01782.x

Borkowski, J. G. \& Burke, J. E. (1996). Theories, models, and measurements of executive functioning. An information processing perspective. In G. R. Lyon \& N. A. Krasnegor (Eds.), Attention, memory and executive function (pp. 235-261). Baltimore, MD, United States: Paul H. Brookes Publishing Company.

Burden, M. J., Jacobson, S. W., Jacobson, J. L. (2005). Relation of prenatal alcohol exposure to cognitive processing speed and efficiency in childhood. Alcoholism: Clinical and Experimental Research, 29, 1473-1483.

Chudley, A. E., Conry, J., Cook, J. L., Lock, C., Rosales, T., \& LeBlanc, N. (2005). Fetal alcohol spectrum disorder, Canadian guidelines for diagnosis. Canadian Medical Association Journal, 172, s1-s21. doi: 10.1503/cmaj.1040302

Clarren, S. K. \& Smith, D. W. (1978). The fetal alcohol syndrome. New England Journal of Medicine, 298, 1063-1067.

Coles, C. D., Platzman, K. A., Lynch, M. E., \& Freides, D. (2002). Auditory and visual sustained attention in adolescents prenatally exposed to alcohol. Alcoholism: Clinical and Experimental Research, 26, 263-271.

Coles, C. D., Platzman, K. A., Raskind-Hood, C. L., Brown, R. T., Faek, A., \& Smith, I. E. (1997). A comparison of children affected by prenatal alcohol exposure and attention deficit, hyperactivity disorder.
Alcoholism: Clinical and Experimental Research, 21, 150-161.

Conry, J. (1990). Neuropsychological deficits in fetal alcohol syndrome and fetal alcohol effects. Alcoholism: Clinical and Experimental Research, 14, 650-655.

Duncan, J., Schramm, M., Thompson, R., \& Dumontheil, I. (2012). Task rules, working memory, and fluid intelligence. Psychonomic Bulletin and Review, 19, 864-870. doi: 10.3758/s13423-012-0225-y

Edward S. C., Jedrychowski, W., Butscher, M., Camann, D., Kieltyka, A., Mroz, E., . . . Perera, F. (2010). Prenatal exposure to airborne polycyclic aromatichydrocarbons and children's intelligence at 5 years of age in a prospective cohort study in Poland. Environmental Health Perspectives, 118, 1326-1331.

Hannigan, J. H., Chiodo, L. M., Sokol, R. J., Janisses, J., Ager, J. W., Greenwald, M. D., \& Delaney-Black, V. (2010). A 14-year retrospective maternal report of alcohol consumption in pregnancy predicts pregnancy and teen outcomes. Alcohol, 44, 583-594. doi: 10.1016/j.alcohol.2009.03.003

Hoyme, H. E., May, P. A., Kalberg, W. O., Kodituwakku, P., Gossage, J. P., Trujillo, P. M. ... Robinson, L. K. (2005). A practical clinical approach to diagnosis of fetal alcohol spectrum disorders, clarification of the 1996 Institute of Medicine criteria. Pediatrics, 115, 39-47. doi: 10.1542/peds.2004-0259

Janzen, L. A., Nanson, J. L., \& Block, G. W. (1995). Neuropsychological evaluation of preschoolers with fetal alcohol syndrome. Neurotoxicology and Teratology, 17, 273-279.

Jacobson, S. W., Jacobson, J. L., Sokol, R. J., Chiodo, L. M., \& Corobana, R. (2004). Maternal age, alcohol abuse history, and quality of parenting as moderators of the effects of prenatal alcohol exposure on 7.5-year intellectual function. Alcoholism: Clinical and Experimental Research, 28, 1732-1745.

Jones, K. L. \& Smith, D. W. (1973). Recognition of the Fetal Alcohol Syndrome in early infancy. Lancet, 2, 999-1001.

Jones, K. L., Smith, D. W., Ulleland, C. N., \& Streissguth, A. P. (1973). Pattern of malformation in offspring of chronic alcoholic mothers. Lancet, 1, 1267-1271.

Kaemingk, K. L., Mulvaney, S., \& Halverson, P.T. (2003). Learning following prenatal alcohol exposure. Performance on verbal and visual multi-trial tasks. Archives of Clinical Neuropsychology, 18, 33-47.

Kalberg, W. O., Provost, B., Tollison, S. J., Tabachnick, B. G., Robinson, L. K., Hoyme, H. E., ... May, P. A. (2006). Comparison of motor delays in young children with fetal alcohol syndrome to those with prenatal alcohol exposure and with no prenatal alcohol exposure. Alcoholism: Clinical and Experimental Research, 30, 2037-2045.

King, A. C. (1994). Enhancing the self-report of alcohol consumption in the community, two questionnaire formats. American Journal of Public Health, 84, 294296.

Kodituwakku, P., Coriale, G., Fiorentino, D., Aragon, A. S., Kalberg, W. O., Buckley, D., . . . May, P. A. (2006). Neurobehavioral characteristics of children 
with fetal alcohol spectrum disorders in communities from Italy: Preliminary results. Alcoholism: Clinical and Experimental Research, 30, 1551-1561.

Kodituwakku, P. W. (2009). Neurocognitive profile in children with fetal alcohol spectrum disorders. Developmental Disabilities Research Reviews, 15, 218-224. doi: 10.1002/ddrr.73

Kodituwakku, P. W., Handmaker, N. S., Cutler, S. K., Weathersby, E. K., \& Handmaker, S. D. (1995). Specific impairments in self-regulation in children exposed to alcohol prenatally. Alcoholism: Clinical and Experimental Research, 19, 1558-1564.

Kodituwakku, P. W., Kalberg, W. O., \& May, P. A. (2001). The effects of prenatal alcohol exposure on executive functioning. Alcohol Research and Health, 25, 92198.

Kopera-Frye, K., Dehaene, S., \& Streissguth, A. P. (1996). Impairments of number processing induced by prenatal alcohol exposure. Neuropsychologia, 34, 1187-1196.

Korkman, M., Kettunen,S., \& Autti-Ramo, I. (2003). Neurocognitive impairment in early adolescence following prenatal alcohol exposure of varying duration. Child Neuropsychology, 9, 117-128.

Lyon, M. A. (1995). A comparison between WISC-III and WISC-R scores for learning disabilities re-evaluations. Journal of Learning Disabilities, 28, 253-255.

Mattson, S. N., Calarco, K. E., \& Lang, A. R. (2006). Focused and shifting attention in children with heavy prenatal alcohol exposure. Neuropsychology, 20, 361369.

Mattson, S. N., Goodman, A. M., Caine, C., Delis, D., Jones, K. L., \& Riley, E. P. (1999). Executive functioning in children with heavy prenatal alcohol exposure. Alcoholism: Clinical and Experimental Research, 23, 1808-1815.

Mattson, S. N., \& Riley, E. P. (1998). A review of the neurobehavioral deficits in children with fetal alcohol syndrome or prenatal exposure to alcohol. Alcoholism: Clinical and Experimental Research, 22, 279-294.

Mattson, S. N., \& Riley, E. P. (1999). Implicit and explicit memory functioning in children with heavy prenatal alcohol exposure. Journal of International Neuropsychology in Society, 5, 462-471.

Mattson, S. N. \& Roebuck, T. M. (2002). Acquisition and retention of verbal and nonverbal information in children with heavy prenatal alcohol exposure. Alcoholism: Clinical and Experimental Research, 26, 875-882.

Mattson, S. N., Roesch, S. C., Fagerlund, A., Auti-Ramo, I., Jones, K. L., May, P. A., ... The CIFASD. (2010). Toward a neurobehavioral profile of fetal alcohol spectrum disorders. Alcoholism: Clinical and Experimental Research, 34, 1640-1650.

May, P. A., Brooke, L., Gossage, J. P., Croxford, J., Adnams, C., Jones, K. L., . . . Viljoen, D. (2000). Epidemiology of fetal alcohol syndrome in a South African community in the Western Cape Province. American Journal of Public Health, 90, 1905-1912.

May, P. A., Gossage, J. P., Brooke, L. E., Snell, C. L., Marais, A. -S., Hendricks, L. S., ... Viljoen, D. L. (2005). Maternal risk factors for fetal alcohol syndrome in the Western Cape Province of South Africa, a population-based study. American Journal of Public Health, 95, 1190-1199. doi: 10.2105/AJPH. 2003.037093

May, P. A., Gossage, J. P., Marais, A. S., Adnams, C. M., Hoyme, H. E., Jones, K. L., \& Viljoen, D. L. (2007). The epidemiology of fetal alcohol syndrome and partial FAS in a South African community. Drug and Alcohol Dependence, 88, 259-271. doi: 10.1016/ j.drugalcdep.2006.11.007

May, P. A., Gossage, J. P., Marais, A. S., Hendricks, L. S., Snell, C. L., Tabachnick, B. G., ... Viljoen, D .L. (2008). Maternal risk factors for fetal alcohol syndrome and partial fetal alcohol syndrome in South Africa, a third study. Alcoholism: Clinical and Experimental Research, 32, 738-753.

May, P. A., Hymbaugh, K. J., Aase, J. M., \& Samet, J. M. (1983). Epidemiology of fetal alcohol syndrome among American Indians of the southwest. Sociology, and Biology, 30, 374-385.

McGhee, C. L., Bjorkquist, O. A., Riley, E. P., \& Mattson, S. N. (2008). Impaired language performance in young children with heavy prenatal alcohol exposure. Neurotoxicology and Teratology, 31, 71-75.

Nash, K., Rovet, J., Greenbaum, R., Fantus, E., Nulman, I., \& Koren, G. (2006). Identifying the behavioral phenotype in fetal alcohol spectrum disorder, sensitivity, specificity and screening potential. Archives of Women's Mental Health, 9, 181-186.

Palmer, C. (1985). Fetal alcohol effects - incidence and understanding in the Cape. South African Medical Journal, 68, 779-780.

Raven, J. C. (1947). Raven coloured progressive matrices. Oxford, United Kingdom: Oxford Psychologists Press.

Robinson, M. (1989). Junior South African Individual Scales (JSAIS). Pretoria, South Africa: Human Sciences Research Council.

Roebuck-Spencer, T. M., \& Mattson, S. N. (2004). Implicit strategy affects learning in children with heavy prenatal alcohol exposure. Alcoholism: Clinical and Experimental Research, 28, 1424-1431.

Sattler, J. M. (2001). Assessment of children, cognitive applications ( $4^{\text {th }}$ ed.). La Mesa, CA, United States: Jerome M. Sattler Publisher, Inc.

Schonfeld, A. M., Paley, B., Frankel, F., \& O’Connor, M. J. (2006). Executive functioning predicts social skills following prenatal alcohol exposure. Child Neuropsychology, 1, 439-452.

Sizemore, O., \& Amler, R. (1996). Characteristics of ATSDR's adult and pediatric environmental neurobehavioral test batteries. Neurotoxicology, 17, 229-236

Sobell, L. C., Agrwal, S., Annis, H., Ayala-Velasquez, H., Echeverria, L., Leo, G. I., . . Z Zioikowski, M. (2001). Cross cultural evaluation of two drinking assessment instruments, alcohol timeline follow back and inventory of drinking situations. Substance Use and Misuse, 36, 313-331.

Sobell, L. C., Sobell, M. B., Leo, G. I., \& Cancilla, A. (1988). Reliability of a timeline method. Assessing normal drinker's reports of recent drinking and a 
comparative evaluation across several populations. British Journal of Addiction, 83, 393-402.

Sokol, R. F., \& Clarren, S. K. (1989). Guidelines for use of terminology describing the impact of prenatal alcohol on the offspring. Alcoholism: Clinical and Experimental Research, 13, 597-598.

SPSS 19.0 (2010). Command Syntax Reference. Chicago, Il, United States: SPSS Inc.

Stratton, K. R., Howe, C. J., \& Battaglia, F. C. (1996). Fetal alcohol syndrome diagnosis, epidemiology, prevention, and treatment. Washington, DC, United States: Institute of Medicine.

Steinhausen, .H. -C., \& Spohr, H. -L. (1998). Long-term outcome of children with fetal alcohol syndrome. Psychopathology, behavior, and intelligence. Alcoholism: Clinical and Experimental Research, 22, 334-338.

Streissguth, A. P. (2007). Offspring effects of prenatal alcohol exposure from birth to 25 years. The Seattle prospective longitudinal study. Journal of Clinical Psychology in Medical Settings, 14, 81-101.

Streissguth, A. P., Bookstein, F. L., Barr, H. M., Press, S., \& Sampson, P. D. (1998). A fetal alcohol behavior scale. Alcoholism: Clinical and Experimental Research, 22, 325-333

Streissguth, A. P., Bookstein, F. L., Barr, H. M., Sampson, P. D., O’Malley, K., \& Young, J. K. (2004). Risk factors for adverse life outcomes in fetal alcohol syndrome and fetal alcohol effects. Journal of Developmental and Behavioral Pediatrics, 25, 228238.

Streissguth, A. P., Clarren, S. K., \& Jones, K. L. (1985). Natural history of the fetal alcohol syndrome. A tenyear follow-up of eleven patients. Lancet, 2, 85-92.

Thomas, S. E., Kelly, S. J., Mattson, S. N., \& Riley, E. P. (1998). Comparison of social abilities of children with fetal alcohol syndrome to those of children with similar IQ scores and normal controls. Alcoholism: Clinical and Experimental Research, 22, 528-533.

Urban, M., Chersich, M. F., Fourie, L .A., Chetty, C., Olivier, L., \& Viljoen, D. (2008). Fetal alcohol syndrome among grade 1 schoolchildren in Northern Cape Province: Prevalence and risk factors. South African Medical Journal, 98, 877-882.

Viljoen, D. L., Craig, P., Hymbaugh, K., Boyle, C., \& Blount, S. (2003). Fetal Alcohol Syndrome - South Africa, 2001. Morbidity and Mortality Weekly Report, 52, 660-662.

Viljoen, D. L., Croxford, J., Gossage, J. P., \& May, P. A., (2002). Characteristics of mothers of children with Fetal Alcohol Syndrome in the Western Cape Province of South Africa, a case control study. Journal of Studies on Alcohol, 63, 6-17.

Viljoen, D. L., Gossage, J. P., Adnams, C. M., Jones, K. L., Robinson, L. K., Hoyme, H. E., . . May, P. A. (2005). Fetal alcohol syndrome epidemiology in a South African community: A second study of a very high prevalence area. Journal of Studies on Alcohol, 66, 593-604.

Wang, P. \& Bellugi, U., (1994). Evidence from two genetic syndromes for dissociation between verbal and visual- spatial short-term memory. Journal of Clinical and Experimental Neuropsychology, 16, 317-322.

Warren, K., Floyd, L., Calhoun, F., Stone, D., Bertrand, J., \& Streissguth, A. (2004). Consensus statement on FASD. Washington, DC, United States: National Organization of Fetal Alcohol Syndrome.

Wechsler, D. (2003). Wechsler Intelligence Scale for Children-4th Edition (WISC-IV®). San Antonio, TX, United States: Harcourt Assessment.

Whaley, S. E., O’Connor, M. J., \& Gunderson, B. (2001). Comparison of the adaptive functioning of children prenatally exposed to alcohol to a non-exposed clinical sample. Alcoholism: Clinical and Experimental Research, 25, 1018-1024. 